\title{
Nosocomial sepsis and drug susceptibility pattern among patients admitted to adult intensive care unit of Ayder Comprehensive Specialized Hospital, Northern Ethiopia
}

Tsega Cherkos Dawit, Reiye Esayas Mengesha, Mohamedawel Mohamedniguss Ebrahim*, Mengistu Hagazi Tequare and Hiluf Ebuy Abraha

\begin{abstract}
Objective: Developing nosocomial sepsis within intensive care unit (ICU) is associated with increased mortality, morbidity, and length of hospital stay. But information is scarce regarding nosocomial sepsis in intensive care units of Northern Ethiopia. Hence, this study aims to determine the incidence of nosocomial sepsis, associated factors, bacteriological profile, drug susceptibility pattern, and outcome among patients admitted to the adult ICU of Ayder Comprehensive Specialized Hospital (ACSH), which is the largest tertiary hospital in Northern Ethiopia.

Method: Facility-based longitudinal study was conducted by following 278 patients who were admitted for more than $48 \mathrm{~h}$ to adult ICU of ACSH, from October 2016 to October 2017. Data were collected from charts, electronic medical records, and microbiology registration book using a checklist. The collected data were subjected to descriptive statistics and multivariable logistic regression using SPSS version 25. Statistical significance was declared at $p<0.05$.

Result: Of all the patients, 60 (21.6\%) of them acquired nosocomial sepsis. The risk of mortality was about two times higher among adult ICU patients who acquired nosocomial sepsis $(R R=2.2 ; 95 \% \mathrm{Cl}$ of $R R=1.3-3.5 ; p=0.003)$. The odds of acquiring nosocomial sepsis among those who were on a mechanical ventilator (MV) and stayed more than a week were 5.7 and 9.3 times higher, respectively, than their corresponding counterparts. Among 48 isolates, Klebsiella was the most common pathogen. The isolates had a broad antibiotic resistance pattern for cephalosporins, penicillins, and methicillin.
\end{abstract}

Conclusion: The incidence of nosocomial sepsis in the adult ICU patients of ACSH was higher when compared to the incidence reported from some African and Asian countries. Mortality was higher among patients who acquired nosocomial sepsis. Use of MV and longer length of ICU stay were the significant predictors of nosocomial sepsis. The isolates were resistant to several antibiotics. Therefore, strict application of infection prevention strategies and appropriate use of antibiotics is so crucial. As well, priority should be given to patients who develop nosocomial sepsis in ICU.

Keywords: Drug susceptibility, Intensive care unit, Mortality, Nosocomial sepsis

*Correspondence: mohamedawel@gmail.com

College of Health Sciences, Mekelle University, Mekele, Ethiopia

\section{Background}

Sepsis is defined as systemic inflammatory response manifested by either hyperthermia or hypothermia, tachypnoea, leukocytosis, or leukopenia in the presence 
of proven or presumed infection [1]. Nosocomial sepsis is also defined as sepsis developing after $48 \mathrm{~h}$ of patient hospitalization [2]. Though it varies with geography and population characteristics, the most common pathogenic gram-positive bacteria causing nosocomial sepsis in intensive care unit (ICU) is Staphylococcus aureus, while organisms such as Klebsiella, Acinetobacter, Pseudomonas, and Escherichia coli species constitute the most common gram-negative species [3-7].

Developing nosocomial sepsis is common in critical care units and its prevalence can range from 9.6 to $17.7 \%$ [7-9]. Factors that predispose to the development of nosocomial sepsis in adult ICU patients are immunosuppression, prolonged hospitalization, intensive use of various equipment (e.g., catheter and mechanical ventilator (MV)), and old age $[1,8,9]$. The most common type of infections in the ICU are ventilator-associated pneumonia (VAP), central lineassociated bloodstream infection (CLABSI), urinary catheter-related infection, and surgical site infection (SSI) [8-10]. Developing nosocomial sepsis within ICU is associated with increased mortality, morbidity, and length of hospital stay $[7,8]$.

In Ethiopia, the incidence of nosocomial sepsis is reported to be higher in intensive care units than inpatient wards $[11,12]$. Evidence show that the prevalence of nosocomial sepsis in Ethiopia ranges from 26 to 36\% [12, 13]. Studies made in teaching hospitals of Ethiopia also have identified older age, immunocompromising conditions, being on $\mathrm{MV}$, chest tube, central-line catheters, and surgery as factors that increase the odds of hospitalacquired infection (HAI) $[11,14,15]$. At hospital level, a study done in the Amhara regional state of Ethiopia reported Klebsiella species and Staphylococcus aureus as the most commonly isolated HAI-causing pathogens [15]. But in surgical ward and surgical ICU, Pseudomonas aeruginosa and Escherichia coli are the major causes of HAI [13].

As a result, in Ethiopia, there are inconsistencies regarding the burden of nosocomial sepsis and the type of isolates causing nosocomial sepsis. Besides, these studies are not specific to adult ICU. Therefore, it is difficult to generalize their findings to adult ICU patients. Furthermore, some of the studies are outdated and information regarding antibiotic resistance is limited. Particularly, there is no such information in the Tigray regional state of Ethiopia. Hence, this study aimed to determine the incidence of nosocomial sepsis, associated factors, bacteriological profile, drug susceptibility pattern, and outcome among patients admitted to the adult ICU of Ayder Comprehensive Specialized Hospital (ACSH) which is the largest tertiary hospital in Tigray, Northern Ethiopia.

\section{Methods and materials}

\section{Study area, design, and period}

Ayder Comprehensive Specialized Hospital is located in Mekelle city and started to provide referral and nonreferral clinical services in 2008 to an estimated 8 million population in its catchment areas of Tigray, Afar, and South-eastern parts of the Amhara Regional States. It provides a broad range of medical services to all age groups. Of the services provided, adult ICU holds a role in managing critically ill patients who require at most care and life supportive machines. It is equipped with MVs, defibrillators, perfusers, and other gadgets [16]. Health facility-based longitudinal study was conducted among patients admitted to adult ICU by following them throughout their ICU stay, from October 2016 to October 2017.

\section{Study population}

All patients who stayed more than $48 \mathrm{~h}$ after admission to adult ICU at ACSH during the study period.

\section{Sample size}

For this study, we included all $(\mathrm{n}=294)$ patients who were admitted to adult ICU for more than $48 \mathrm{~h}$ during the study period.

\section{Data collection, source, and quality assurance}

A checklist was developed and used to extract sociodemographic, clinical, and microbiological data. Data were collected from charts, electronic medical records, and microbiology registration books. Data were collected by trained internal medicine residents under the supervision of an internist.

\section{Study variables}

Our outcome variables were nosocomial sepsis, mortality, bacteriological profile, and drug susceptibility. We defined nosocomial sepsis as sepsis developing after $48 \mathrm{~h}$ of ICU admission and it was dichotomized as "Yes" and "No". Age, sex, residence, length of hospital stay, MV use, and central-line use were the independent variables.

\section{Body fluid sample collection and antimicrobial susceptibility testing}

Under aseptic technique, body fluids (i.e., blood, urine, and tracheal secretion) were collected and transported to microbiology unit. Semiquantitative culture technique was used for urine samples. After a loop full of well-mixed and uncentrifuged urine and tracheal aspirate samples were inoculated onto Blood agar (BA) and MacConkey agar (MA), they were aerobically incubated at $37{ }^{\circ} \mathrm{C}$ for $24 \mathrm{~h}$. Regarding blood samples, they were initially enriched on Brain Heart Infusion broth for $48 \mathrm{~h}$ and 
subsequently cultured on both MA and BA every $24 \mathrm{~h}$ for 3 days.

Next to the isolation of pathogens with colony characteristics, gram staining was performed to categorize isolates as gram positive and gram negative. Catalase, oxidase, coagulase, and optochin sensitivity tests were carried out for further identification of Gram positives. Gram negatives were also further identified using catalase, oxidase, motility, $\mathrm{H}_{2} \mathrm{~S}$ and indole production, citrate utilization, triple sugar iron utilization, urea hydrolysis, and other biochemical tests.

Antimicrobial susceptibility of all isolates was determined by Kirby-Bauer disk diffusion method according to Clinical Laboratory Standard Institute (CLSI) [17]. For gram positive bacteria, the following discs were included: Penicillin G, Ampicillin, Erythromycin, Methicillin, Vancomycin, Ciprofloxacin, Chloramphenicol, Ceftriaxone, Sulphamethaxazole/trimethoprim, Meropenem, and Tetracycline. For gram negatives, Ampicillin, Amoxicillin/ Clavulanic acid, Ciprofloxacin, Tetracycline, Gentamycin, Sulphamethaxazole/trimethoprim, Chloramphenicol, Ceftriaxone, Ceftazidime, Meropenem, Cephalothin, Amikacin, Piperacillin, and Tobramycin were used. After measuring and interpreting zone of inhibition using standard chart, the bacteria were labeled as susceptible $(\mathrm{S})$, intermediate (I), or resistant (R).

\section{Data analysis}

Data analyses were carried out using SPSS version 25. Frequency and percentage were employed to summarize categorical variables. Continuous variables were also described using an appropriate combination of measure of central tendency and measure of dispersion. Relative risk with its $95 \%$ confidence interval was calculated to quantify the effect of acquiring nosocomial sepsis on mortality. In addition, association between categorical variables was evaluated using Chi-square test of independence.

The relationship between the acquisition of nosocomial sepsis and its predictors was analyzed using binary logistic regression. Variables with a p-value $<0.25$ in the univariable analysis were selected in the final multivariable logistic regression model. A p-value $<0.05$ was considered to declare a statistical significance. The final multivariable model was checked for the goodness of fit and multicollinearity using Hosmer-Lemeshow test and variance inflation factor (VIF), respectively.

\section{Ethical approval}

Ethical approval of the research was obtained from the Institutional Review Board (IRB) of Mekelle University, College of Health sciences. Permission to collect data was obtained from the chief clinical director's office of ACSH. De-identification was applied by removing names and medical record numbers and replaced with codes.

\section{Results}

A total of 294 patients were admitted to the Adult ICU for more than $48 \mathrm{~h}$ during the study period. Of these, 278/294 (94.6\%) patients with complete data were included. Sixty (21.6\%) patients developed nosocomial sepsis and $48 / 60(80 \%)$ of them had an isolated organism (Fig. 1).

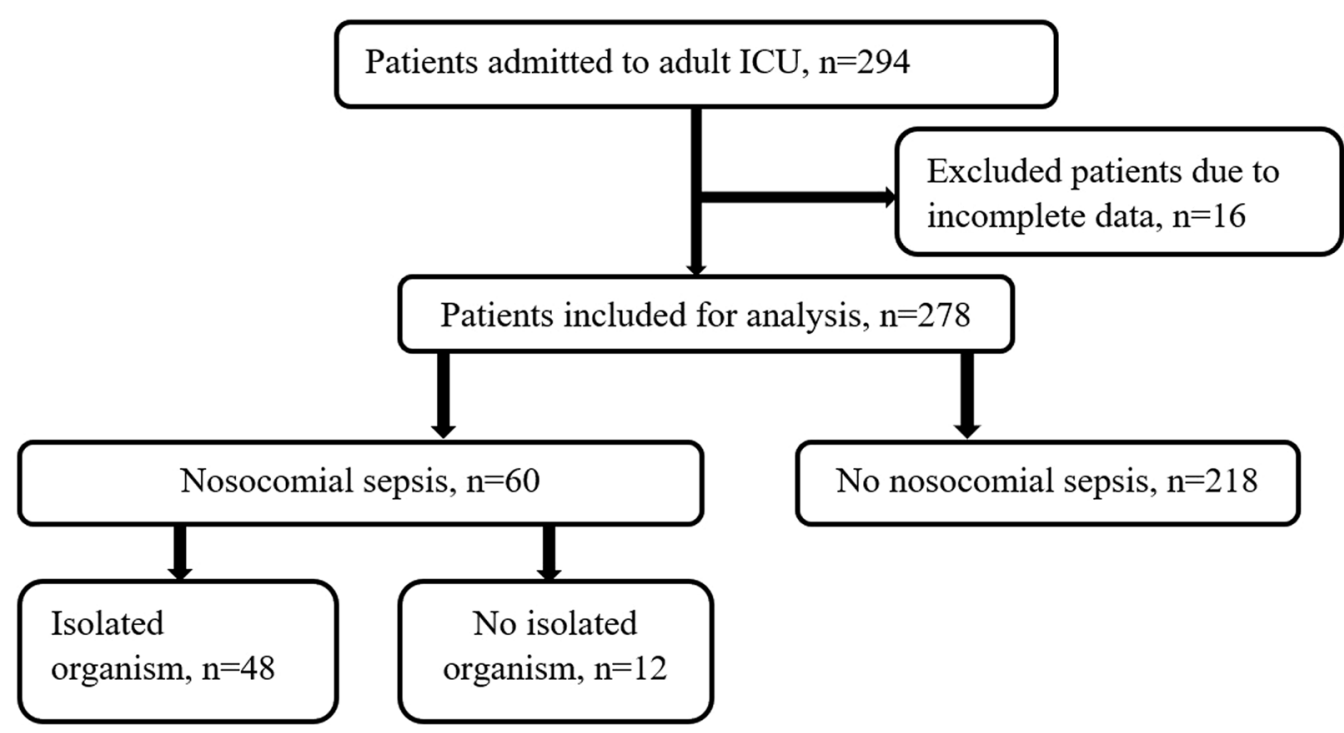

Fig. 1 Flow diagram of patient recruitment, nosocomial sepsis, and isolated organisms 


\section{Sociodemographic and clinical characteristics}

The median age of the participants was $42(\mathrm{IQR}=31)$ years. Out of the patients included in the study, 156 (56.1\%) were male and 163 (58.6\%) were from an urban area (Table 1).

Among the reasons for ICU admission, cardiovascular, neurologic, and respiratory conditions accounted for 88 (31.7\%), 65 (23.4\%), and 44 (14.4\%), respectively. Of the cardiovascular conditions, acute coronary syndrome accounted for 53/88 (60.2\%). Concerning neurologic conditions, head injury, stroke, and Guillain-Barre

Table 1 Sociodemographic and clinical characteristics of the study participants adult ICU, ACSH, $2017(n=278)$

\begin{tabular}{|c|c|c|}
\hline Variables & Frequency & Percentage $(95 \% \mathrm{Cl})$ \\
\hline \multicolumn{3}{|l|}{ Age in years } \\
\hline$<40$ & 123 & $44.2(38.5-50.1)$ \\
\hline $40-64$ & 120 & $43.2(37.4-49.1)$ \\
\hline $65+$ & 35 & $12.6(9.2-17.1)$ \\
\hline \multicolumn{3}{|l|}{ Sex } \\
\hline Female & 122 & $43.9(38.1-49.8)$ \\
\hline Male & 156 & $56.1(50.2-61.9)$ \\
\hline \multicolumn{3}{|l|}{ Residence } \\
\hline Urban & 163 & $58.6(52.7-64.3)$ \\
\hline Rural & 115 & $41.4(35.7-47.3)$ \\
\hline \multicolumn{3}{|c|}{ Mechanical ventilator use } \\
\hline Yes & 89 & $32.0(26.8-37.8)$ \\
\hline No & 189 & $68.0(62.2-73.2)$ \\
\hline \multicolumn{3}{|l|}{ Central line use } \\
\hline Yes & 25 & $9.0(6.1-13.0)$ \\
\hline No & 253 & $91.0(87.0-93.9)$ \\
\hline \multicolumn{3}{|c|}{ Urinary catheterization } \\
\hline Yes & 259 & $93.2(89.5-95.6)$ \\
\hline No & 19 & $6.8(4.4-10.5)$ \\
\hline \multicolumn{3}{|l|}{ Length of stay (days) } \\
\hline 2-7 days & 188 & $67.6(61.9-72.9)$ \\
\hline$>7$ & 90 & $32.4(27.1-38.1)$ \\
\hline \multicolumn{3}{|l|}{ Nosocomial sepsis } \\
\hline Yes & 60 & $21.6(17.1-26.8)$ \\
\hline No & 218 & $78.4(73.2-82.9)$ \\
\hline \multicolumn{3}{|c|}{ Focus of infection $(n=60)$} \\
\hline Respiratory & 47 & $78.3(65.8-87.2)$ \\
\hline Urinary & 10 & $16.7(9.0-28.7)$ \\
\hline Thrombophlebitis & 3 & $5.0(1.6-14.8)$ \\
\hline \multicolumn{3}{|l|}{ Overall outcome } \\
\hline Died & 51 & $18.3(14.2-23.4)$ \\
\hline Discharged & 227 & $81.7(76.6-85.8)$ \\
\hline \multicolumn{3}{|c|}{ Nosocomial sepsis outcome $(n=60)$} \\
\hline Died & 19 & $31.6(20.9-44.8)$ \\
\hline Discharged & 41 & $68.3(55.2-79.1)$ \\
\hline
\end{tabular}

ACSH Ayder Comprehensive Specialized Hospital, ICU intensive care unit syndrome accounted for 29/65 (44.6\%), 15/65 (23.1\%) and $12 / 65$ (18.5\%), correspondingly. Pulmonary thromboembolism contributed for 13/44 (29.5\%) of the respiratory admissions. Regarding admissions due to infectious conditions, tetanus and severe malaria accounted for $32 \%$ and $16 \%$ of cases, respectively. The remaining admission conditions include endocrine, gastrointestinal diseases, poisoning, electrolyte derangement, and intra-operative complications.

Nearly one-third of the study participants were on MV and only $9.0 \%$ of them required central-line use. For twothird of the patients, length of ICU stay was 1 week or less. Regarding urinary catheterization, all patients were catheterized, except 19 (6.8\%) (Table 1). Among the noncatheterized patients, no individual developed nosocomial sepsis. In other words, all those who developed nosocomial sepsis were catheterized and there was a significant association between catheterization and nosocomial sepsis $\left(\chi^{2}(N=278, d f=1)=5.6, p=0.018\right)$.

\section{Nosocomial sepsis and mortality}

Of all the patients, $60(21.6 \%)$ acquired nosocomial sepsis. For the patients with nosocomial sepsis, the main focuses of infection were respiratory (78.3\%) and urinary $(16.7 \%)$ (Table 1$)$. The risk of mortality was about two times higher among those who acquired nosocomial sepsis $($ Risk ratio $(R R)=2.2 ; 95 \%$ CI of $R R=1.3-3.5$; $p=0.003)$.

Based on multivariable logistic regression model, the variables MV use and length of ICU stay were significantly associated with the nosocomial sepsis. Thus, the odds of acquiring nosocomial sepsis among those who were on MV were 5.7 times (AOR (95\% CI) 5.7 (2.612.7), $p<0.001)$ higher than their counterparts. Those who stayed more than a week in the ICU had about nine times higher odds of nosocomial sepsis acquisition (AOR (95\% CI) 9.3 (4.3-20.4), $p<0.001$ ). The final multivariable model was good fit for the data (Hosmer-Lemeshow test: $\left.\chi^{2}=10.97, d f=8, p=0.204\right)$ and had no multicollinearity issue ( $\max \mathrm{VIF}=1.2$, mean VIF $=1.1)$. ROC curve analysis revealed that the final model had very good accuracy with the area under the curve of 0.873 (Table 2).

\section{Microbiological profile of isolated samples}

Samples were taken from blood, urine, and tracheal secretion of septic patients in the ICU. Of the samples taken, 48 isolates of organisms were found, of which $44 / 48$ (91.7\%) were gram-negative. The only gram-positive isolate was Staphylococcus aureus and accounted for $4 / 48$ (8.3\%). From the total isolates, Klebsiella was found to be the most common micro-organism identified, 18/48 (37.5\%) (Fig. 2). 
Table 2 Factors associated with the acquisition of nosocomial sepsis, adult ICU, ACSH, $2017(n=278)$

\begin{tabular}{|c|c|c|c|c|}
\hline Variables & COR $(95 \% \mathrm{Cl})$ & p-value & AOR $(95 \% \mathrm{CI})$ & p-value \\
\hline \multicolumn{5}{|c|}{ Age in years } \\
\hline$<40$ & 1 & & 1 & \\
\hline $40-64$ & $0.7(0.4-1.4)$ & 0.333 & $1.3(0.6-3.2)$ & 0.505 \\
\hline $65+$ & $0.5(0.2-1.4)$ & 0.181 & $0.8(0.2-3.3)$ & 0.806 \\
\hline \multicolumn{5}{|l|}{ Sex } \\
\hline Female & 1 & & 1 & \\
\hline Male & $1.6(0.9-2.9)$ & 0.119 & $1.4(0.6-2.9)$ & 0.412 \\
\hline \multicolumn{5}{|l|}{ Residence } \\
\hline Urban & 1 & & 1 & \\
\hline Rural & $1.7(0.9-3.0)$ & 0.069 & $1.6(0.8-3.4)$ & 0.207 \\
\hline \multicolumn{5}{|c|}{ Mechanical ventilator use } \\
\hline Yes & $11.9(6.1-23.2)$ & $<0.001$ & $5.7(2.6-12.7)$ & $<0.001$ \\
\hline No & 1 & & 1 & \\
\hline \multicolumn{5}{|c|}{ Length of stay } \\
\hline 2-7 days & 1 & & 1 & \\
\hline$>7$ days & $16.8(8.2-34.3)$ & $<0.001$ & $9.3(4.3-20.4)$ & $<0.001$ \\
\hline \multicolumn{5}{|c|}{ Central line use } \\
\hline Yes & $1.5(0.6-3.7)$ & 0.416 & $1.1(0.3-3.7)$ & 0.910 \\
\hline No & 1 & & 1 & \\
\hline
\end{tabular}

ACSH Ayder Comprehensive Specialized Hospital, AOR adjusted odds ratio, COR crude odds ratio, ICU intensive care unit

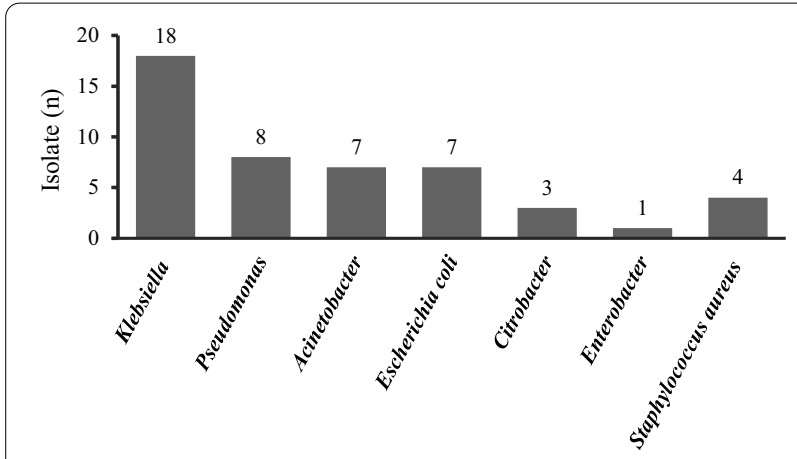

Fig. 2 Isolated microorganisms from the septic patients in adult ICU, ACSH, $2017(n=48)$

The gram-negatives had a broad antibiotic resistance pattern for cephalosporins, penicillins, and meropenem (Table 3). Staphylococcus aureus was also found to be resistant to penicillins and methicillin (Table 4).

\section{Discussion}

Our study aimed at assessing the prevalence of nosocomial sepsis, associated factors, bacteriological profile, drug susceptibility pattern, and outcome of patients admitted to adult ICU of ACSH. The cumulative incidence of nosocomial sepsis in this study was $21.6 \%$. MV use and length of ICU stay were independent predictors of nosocomial sepsis. Mortality was remarkably higher among those who developed nosocomial sepsis. The isolated microorganisms had a broad antibiotic resistance pattern for cephalosporins, penicillins, and meropenem.

The incidence of nosocomial sepsis in our setup was higher compared to studies done in Nigeria (15\%) [8] and India (9.6-17.7\%) [7, 9, 10]. Nosocomial sepsis happens due to inadequate hand hygiene technique, infrequent urinary catheter change, inadequately cleaned ventilator, lack of programmed ICU environment decontamination procedure, and lack of strict attendant visit protocol which make patients susceptible for various infections [18].

Those who were on MV had a higher risk (5.7-fold) of nosocomial sepsis. This finding was in tune with studies done in India $[9,10]$. Additionally, those who stayed more than a week in the ICU had about nine times higher odds of nosocomial sepsis. This higher risk of nosocomial sepsis among those who stayed more than a week could be because of prolonged exposer to MV use. In our study, the use of MV was $64.4 \%$ in those who stayed more than a week in contrast to those who stayed a week and less, which was $16.5 \%$. This difference was statistically significant $\left(\chi^{2}=64.3, d f=1\right.$ and $p<0.001)$. Furthermore, longer ICU stay and MV use are thought to increase the risk of acquiring antibioticresistant infections $[18,19]$.

The overall mortality of ICU patients was $18.3 \%$. But this mortality was significantly higher among those who acquired nosocomial sepsis (31.6\%). Similar results regarding the mortality of patients with nosocomial sepsis are reported from studies done in Asia, Europe, and North America [10, 20-23]. In our study, the presence of nosocomial sepsis contributed considerably to poor outcome by increasing mortality risk significantly. Moreover, studies report that the burden of mortality due to nosocomial sepsis is higher in patients with organ dysfunction and those who had surgery on an emergency basis [21, 23].

Among the body fluid samples taken, 48 isolates of organisms were found, of which $91.6 \%$ were gram-negative and $8.3 \%$ were gram-positive and this finding was consistent with studies carried out in Nigeria, India, and Europe [8, 9, 20, 24]. Klebsiella was found to be the most common micro-organism followed by pseudomonas, Escherichia coli, and Acinetobacter. This is parallel with the studies of Nigeria, India and Fiji [8, 20, 24]. For instance, in Fiji's study, the commonest pathogens isolated were Klebsiella pneumoniae, Acinetobacter, and Pseudomonas [20]. 
Table 3 Distribution of antibiotics susceptibility pattern for isolated gram negative microbials from septic patients in Adult ICU, ACSH, 2017

\begin{tabular}{|c|c|c|c|c|c|c|}
\hline Antibiotic & $\begin{array}{l}\text { Sensitivity } \\
\text { pattern }\end{array}$ & $\begin{array}{l}\text { Klebsiella } \\
\text { sensitivity \% } \\
\text { (isolates no) }\end{array}$ & $\begin{array}{l}\text { Pseudomonas } \\
\text { sensitivity \% } \\
\text { (isolates no) }\end{array}$ & $\begin{array}{l}\text { Escherichia coli } \\
\text { sensitivity \% (isolates } \\
\text { no) }\end{array}$ & $\begin{array}{l}\text { Acinetobacter } \\
\text { sensitivity \% } \\
\text { (isolates no) }\end{array}$ & $\begin{array}{l}\text { Citrobacter } \\
\text { sensitivity \% } \\
\text { (isolates no) }\end{array}$ \\
\hline \multirow[t]{2}{*}{ Ampicillin } & $\mathrm{R}$ & $100(17 / 17)$ & $100(5 / 5)$ & $89(8 / 9)$ & $100(5 / 5)$ & $100(3 / 3)$ \\
\hline & S & - & - & $11(1 / 9)$ & - & - \\
\hline Penicillin & $\mathrm{R}$ & - & - & $100(1 / 1)$ & $100(1 / 1)$ & - \\
\hline \multirow[t]{2}{*}{ Tetracycline } & $\mathrm{R}$ & $90(9 / 10)$ & $100(2 / 2)$ & $83.3(5 / 6)$ & $100(4 / 4)$ & $100(3 / 3)$ \\
\hline & S & 10 & - & 16.7 & - & - \\
\hline \multirow[t]{2}{*}{ Doxycycline } & $\mathrm{R}$ & $66.7(2 / 3)$ & $100(2 / 2)$ & $100(3 / 3)$ & $66.7(2 / 3)$ & $100(1 / 1)$ \\
\hline & S & 33.3 & - & - & 33.3 & - \\
\hline \multirow[t]{2}{*}{ Chloramphenicol } & $\mathrm{R}$ & $71.4(5 / 7)$ & $100(2 / 2)$ & $66.7(2 / 3)$ & $100(3 / 3)$ & $100(3 / 3)$ \\
\hline & S & 28.6 & - & 33.3 & - & - \\
\hline \multirow[t]{3}{*}{ Ciprofloxacin } & $\mathrm{R}$ & $62.5(10 / 16)$ & 30() $3 / 10)$ & $77.8(7 / 9)$ & $83.3(5 / 6)$ & $100(3 / 3)$ \\
\hline & S & 25 & 50 & 11.1 & - & - \\
\hline & I & 12.5 & 20 & 11.1 & 16.7 & - \\
\hline \multirow[t]{3}{*}{ Gentamycin } & $\mathrm{R}$ & $58.3(7 / 12)$ & $57.1(4 / 7)$ & $60(3 / 5)$ & $100(3 / 3)$ & $100(3 / 3)$ \\
\hline & S & 16.7 & 14.3 & 20 & - & - \\
\hline & । & 25 & 28.6 & 20 & - & - \\
\hline Cotrimoxazole & $\mathrm{R}$ & $92.3(12 / 13)$ & $100(2 / 2)$ & $75(3 / 4)$ & $100(3 / 3)$ & $100(3 / 3)$ \\
\hline Augmentin & $\mathrm{R}$ & $100(13 / 13)$ & $100(2 / 2)$ & $100(4 / 4)$ & $100(4 / 4)$ & $100(3 / 3)$ \\
\hline \multirow[t]{3}{*}{ Amikacin } & $\mathrm{R}$ & $60(3 / 5)$ & $25(2 / 8)$ & $100(1 / 1)$ & $100(3 / 3)$ & $100(2 / 2)$ \\
\hline & S & 20 & $37.5(3 / 8)$ & - & - & - \\
\hline & I & 20 & 37.5 (3/8) & - & - & - \\
\hline Cephalothin & $\mathrm{R}$ & $100(12 / 12)$ & $100(1 / 1)$ & $100(4 / 4)$ & $100(2 / 2)$ & $100(1 / 1)$ \\
\hline Piperacillin & $R$ & $100(1 / 1)$ & $25(1 / 3)$ & $100(1 / 1)$ & $100(2 / 2)$ & $100(1 / 1)$ \\
\hline \multirow[t]{2}{*}{ Ceftriaxone } & $\mathrm{R}$ & $100(8 / 8)$ & & $100(1 / 1)$ & $100(4 / 4)$ & $100(1 / 1)$ \\
\hline & $S$ & - & $100(1 / 1)$ & & & - \\
\hline \multirow[t]{2}{*}{ Ceftazidime } & $\mathrm{R}$ & $100(9 / 9)$ & $42.9(3 / 7)$ & $100(1 / 1)$ & $100(5 / 5)$ & $100(1 / 1)$ \\
\hline & $S$ & - & 57.1 & - & & - \\
\hline \multirow[t]{3}{*}{ Meropenem } & $R$ & $10(1 / 10)$ & $50(2 / 2)$ & - & $100(4 / 4)$ & $100(1 / 1)$ \\
\hline & S & $70(7 / 10)$ & 50 & $100(1 / 1)$ & & - \\
\hline & I & 20 & - & - & - & - \\
\hline \multirow[t]{3}{*}{ Tobramycin } & $R$ & $66.7(2 / 3)$ & $42.8(3 / 5)$ & - & - & - \\
\hline & $S$ & 33.3 & 28.6 & - & - & - \\
\hline & I & - & 28.6 & - & - & - \\
\hline \multirow[t]{2}{*}{ Cefepime } & $\mathrm{R}$ & $100(3 / 3)$ & - & - & $100(4 / 4)$ & - \\
\hline & $S$ & - & $100(3 / 3)$ & & - & - \\
\hline
\end{tabular}

$R$ resistant, $S$ susceptible, I intermediate, $A C S H$ Ayder Comprehensive Specialized Hospital, ICU intensive care unit

Klebsiella was resistant to ampicillin, ceftazidime, and cefepime in all tested isolates and showed a broad resistance pattern to other antibiotics, but was found to be sensitive to meropenem in $66.7 \%$. Pseudomonas had a sensitivity of $57.1 \%$ and $50 \%$ to ceftazidime and meropenem respectively. Higher resistance to meropenem was found in Acinetobacter, where all 4 isolates were resistant to the antibiotic. The isolated Staphylococcus aureus was also methicillin-resistant but vancomycin sensitive. These results indicate that there is a broad resistance to penicillin, cephalosporins, and other antibiotics in our adult ICU. Such kind of broad resistance is reported by several studies done in ICU of different countries [25-36].

The use of antibiotics to patients should be evidencebased during a highly suspected infection and bacteriologic evidence of infection. Frequent use of antibiotics in patients with or without sepsis renders most organisms to be antibiotic-resistant. When indicated, the use of antibiotics should be guided with a bacteriological 
Table 4 Distribution of antibiotics susceptibility pattern for isolated Staphylococcus aureus from septic patients in adult ICU, ACSH, 2017

\begin{tabular}{lll}
\hline Antibiotic & $\begin{array}{l}\text { Sensitivity } \\
\text { pattern }\end{array}$ & $\begin{array}{l}\text { Staphylococcus aureus } \\
\text { sensitivity \% (isolates } \\
\text { no) }\end{array}$ \\
\hline Penicillin & $\mathrm{R}$ & $100(3 / 3)$ \\
Tetracycline & $\mathrm{S}$ & $100(1 / 1)$ \\
Doxycycline & $\mathrm{R}$ & $33.3(1 / 3)$ \\
Chloramphenicol & $\mathrm{S}$ & $66.7(2 / 3)$ \\
Ciprofloxacin & $\mathrm{R}$ & $100(1 / 1)$ \\
Gentamycin & $\mathrm{R}$ & $100(1 / 1)$ \\
Cotrimoxazole & $\mathrm{R}$ & $100(2 / 2)$ \\
Ceftriaxone & $\mathrm{R}$ & $100(1 / 1)$ \\
Erythromycin & $\mathrm{R}$ & $100(2 / 2)$ \\
Vancomycin & $\mathrm{R}$ & $100(2 / 2)$ \\
& $\mathrm{R}$ & - \\
Methicillin & $\mathrm{S}$ & $66.7(2 / 3)$ \\
\hline
\end{tabular}

$R$ resistant, $S$ susceptible, / intermediate, $A C S H$ Ayder Comprehensive Specialized Hospital, ICU intensive care unit

profile. Providing drugs to a patient harboring resistant microorganisms has negative impacts including financial burden, longer hospital stay, deterioration, and death of the patient $(18,19)$.

\section{Conclusion}

There is a higher incidence of sepsis in our adult ICU compared to the incidence reported from some African and Asian countries. Use of MV and longer length of inhospital stay were significant risk factors for nosocomial sepsis. Furthermore, nosocomial septicaemia had a significant effect on mortality. The identified organism were mainly gram negatives.

\section{Limitations of the study}

Body fluid culture was not done for all patients. In addition, antibiotic sensitivity test was inconsistent across each group of organisms (i.e., gram negative and gram positive).

\section{Recommendation}

Great emphasis should be given to the high incidence of nosocomial sepsis. Setting up motivated and persistent infection prevention techniques is required. This includes developing strict protocols and practice which is adherent to the protocol. These include adequate cleaning of mechanical ventilators and other devices before and after use in a patient. The use of antibiotics should be guided with appropriate clinical sepsis diagnosis and basing the selection on the bacteriological profile of the patient. As well, hospital management and policymakers like the ministry of health should give priority to this higher incidence of nosocomial sepsis in ICU and reinforce existing infection prevention and control strategies of Ethiopia. Besides, nosocomial sepsis management guidelines need to be developed based on available published and unpublished local research works and continuous nosocomial sepsis surveillance should be considered to assess the trend.

\section{Abbreviations \\ ACSH: Ayder Comprehensive Specialized Hospital; AOR: Adjusted odds ratio; BA: Blood agar; CLABSI: Central line-associated bloodstream infection; CLSI: Clinical Laboratory Standard Institute; COR: Crude odds ratio; HAl: Hospital acquired infection; ICU: Intensive care unit; IQR: Inter-quartile range; IRB: Insti- tutional Review Board; MA: MacConkey agar; MV: Mechanical ventilator; ROC: Receiver operating characteristic; RR: Risk ratio; SSI: Surgical site infection; VAP: Ventilator-associated pneumonia; VIF: Variance inflation factor.}

\section{Acknowledgements}

We would like to forward our gratitude to Mr. Alemseged, the staffs of Intensive Care Unit (ICU) and Microbiology Unit, Dr. Reiye Esayas, data collectors, and card room members. We would also like to thank the Institutional Review Board of Mekelle University, College of Health Sciences.

\section{Authors' contributions}

TCD, MME, and HEA wrote the main manuscript as well as prepared the tables. All authors reviewed the manuscript. All authors read and approved the final manuscript.

\section{Funding}

No funding available.

\section{Availability of data and materials}

The datasets used and/or analysed during the current study available from the corresponding author on reasonable request.

\section{Declarations}

Ethics approval and consent to participate

Ethical approval of the research was obtained from the Institutional Review Board (IRB) of Mekelle University, College of Health sciences. Permission, to collect secondary data, was obtained from the chief clinical director's office of ACSH. Informed consent was not applicable since secondary data used. But deidentification was applied by removing names and medical record numbers, and finally replacing them with codes. All methods are done in accordance with relevant guidelines and regulations.

\section{Consent for publication}

Not applicable.

Competing interests

The authors declare that they have no competing interests.

Received: 11 February 2021 Accepted: 31 July 2021

Published online: 17 August 2021

\section{References}

1. FB Mayr, S Yende, DC Angus. Epidemology of severe sepsis: PA, USA. 2014

2. $\mathrm{WHO} / \mathrm{CDS} / \mathrm{CSR} / \mathrm{CDH}$. A practical guideline, 2nd edition, WHO, Department of Communicable Disease, Surveillance and response. 2002;12. 
3. Finfer S, Bellomo R, Lipman J, French C, Dobb G, Myburgh J. Adult-population incidence of severe sepsis in Australian and New Zealand intensive care units. Intensive Care Med. 2004;30(4):589-96.

4. Vincent JL, Sakr Y, Sprung CL, Ranieri VM, Reinhart K, Gerlach H, Moreno $\mathrm{R}$, Carlet J, Le Gall JR, Payen D, Sepsis Occurrence in Acutely III Patients Investigators. Sepsis in European intensive care units: results of the SOAP study. Crit Care Med. 2006;34:344-53.

5. Orsini J, Mainardi C, Muzylo E, Karki N, Cohen N, Sakoulas G. Microbiological profile of organisms causing bloodstream infection in critically ill patients. J Clin Med Res. 2012;4(6):371.

6. Barantsevich E, Barantsevich N, Rybkova N, Churkina I, Pestova N, Karpenko M. Etiological agents of bacterial sepsis in a newly constructed medical center in Saint Petersburg, Russia. Crit Care. 2011;15(S3):P45.

7. Mythri H, Kashinath KR. Nosocomial infections in patients admitted in intensive care unit of a Tertiary Health Center, India. Ann Med Health Sci Res. 2014;4(5):738-41.

8. Arinola S, Babatunde O, Samuel F, Victor N, Akinola A, et al. Epidemiology of bacteria colonization and ICU-acquired infection in a Nigerian Tertiary Hospital. 2012.

9. Pradhan NP, Bhat SM, Ghadage DP. Nosocomial infections in the medical ICU: a retrospective study highlighting their prevalence, microbiological profile and impact on ICU stay and mortality. J Assoc Physicians India. 2014;62(10):18-21.

10. Sheth KV, Patel TK, Malek SS, Tripathi CB. Antibiotic sensitivity pattern of bacterial isolates from the intensive care unit of a tertiary care hospital in India. Trop J Pharm Res. 2012;1 (6):991-9.

11. Ali S, Birhane M, Bekele S, Kibru G, Teshager L, Yilma Y, et al. Healthcare associated infection and its risk factors among patients admitted to a tertiary hospital in Ethiopia: Iongitudinal study. Antimicrob Resist Infect Control. 2018;7(1):1-9.

12. Alemu AY, Endalamaw A, Belay DM, Mekonen DK, Birhan BM, Bayih WA. Healthcare-associated infection and its determinants in Ethiopia: a systematic review and meta-analysis. PLoS ONE. 2020;15(10):e0241073.

13. Endalafer N, Gebre-Selassie S, Kotiso B. Nosocomial bacterial infections in a tertiary hospital in Ethiopia. J Infect Prev. 2011;12(1):38-43.

14. Yallew WW, Kumie A, Yehuala FM. Risk factors for hospital-acquired infections in teaching hospitals of Amhara regional state, Ethiopia: a matchedcase control study. PloS one. 2017;12(7):e0181145.

15. Yallew WW, Kumie A, Yehuala FM. Point prevalence of hospital-acquired infections in two teaching hospitals of Amhara region in Ethiopia. Drug Healthc Patient Saf. 2016;8:71.

16. Ayder Comprehensive Specialized Hospital-Mekelle University Profile: 2020.

17. CLSI. Performance standards for antimicrobial susceptibility testing: Twenty-fifth informational supplement. Pittsburgh: Clinical and Laboratory Standards Institute; 2015

18. Delia M, Monica L. Infections and multidrug-resistant pathogens in ICU patients. 2018.

19. Varley AJ, Williams $H$, Fletcher $\mathrm{S}$. Antibiotic resistance in the intensive care unit. Contin EducAnaesth Crit Care Pain. 2009;9(4):114-8.

20. Naidu K, Nabose I, Ram S, Viney K, Graham SM, Bissell K. A descriptive study of nosocomial infections in an adultintensive care unit in Fiji: 201112. JTrop Med. 2014. https://doi.org/10.1155/2014/545160

21. ÇAllk ş, Arl A, Avcl M, DurAn FY, TopÇu B. Investigation of mortality predictors in general intensive care unitpatients with nosocomial sepsis: a retrospective cohort study. J Tepecik Educ Res Hosp.2017;27(1):25-30.
22. Alberti C, Brun-Buisson C, Burchardi H, Martin C, Goodman S, Artigas A, et al. Epidemiology of sepsis and infection in ICU patients from an international multicentre cohort study. Intensive Care Med. 2002;28(2):108-21.

23. Markwart R, Saito H, Harder T, Tomczyk S, Cassini A, Fleischmann-Struzek C, Reichert F, Eckmanns T, Allegranzi B. Epidemiology and burden of sepsis acquired in hospitals and intensive care units: a systematic review and meta-analysis. Intensive Care Med. 2020. https://doi.org/10.1007/ s00134-020-06106-2

24. Vincent JL, Rello J, Marshall J, Silva E, Anzueto A, Martin CD, et al. International study of the prevalence and outcomes of infection in intensive care units. JAMA. 2009;302(21):2323-9.

25. Cantón R, Gijón D, Ruiz-Garbajosa P. Antimicrobial resistance in ICUs: an update in the light of the COVID-19 pandemic. Curr opin crit care. 2020;26(5):433-41.

26. Zhanel GG, DeCorby M, Laing N, Weshnoweski B, Vashisht R, Tailor F, et al. Antimicrobial-resistant pathogens in intensive care units in Canada: results of the Canadian National Intensive Care Unit (CAN-ICU) study, 2005-2006. Antimicrob Agents Chemother. 2008:52(4):1430-7.

27. Zhanel GG, DeCorby M, Adam H, Mulvey MR, McCracken M, LagacéWiens $P$, et al. Prevalence of antimicrobial-resistant pathogens in Canadian hospitals: results of the Canadian Ward Surveillance Study (CANWARD 2008). Antimicrob Agents Chemother. 2010;54(11):4684-93.

28. Bhatia A, Kalra J, Kohli S, Kakati B, Kaushik R. Antibiotic resistance pattern in intensive care unit of a tertiary care teaching hospital. IJBCP Int J Basic Clin Pharmacol. 2018;7(5):906-11.

29. Bhandari P, Thapa G, Pokhrel BM, Bhatta DR, Devkota U. Nosocomial isolates and their drug resistant pattern in ICU patients at national institute of neurological and allied sciences, Nepal. 2015;2015.

30. Saxena S, Priyadarshi M, Saxena A, Singh R. Antimicrobial consumption and bacterial resistance pattern in patients admitted in I. C. U. at a tertiary care center. J Infect Public Health. 2019;12(5):695-9. https://doi.org/10. 1016/j.jiph.2019.03.014.

31. Jones RN. Resistance patterns among nosocomial pathogens * trends over the past few years. Chest. 2001;119(2):397S-404S. https://doi.org/10. 1378/chest.119.2_suppl.397S.

32. Mehta RM, Niederman MS. Antibiotic resistance in the intensive care unit. Berlin: Springer; 2001.

33. MacVane SH. Antimicrobial resistance in the intensive care unit: a focus on gram-negative bacterial infections.J Intensive Care Med. 2017:32(1):25-37.

34. Webb A, Angus D, Finfer S, Gattinoni L, Singer M, Care C. Antibiotic resistance in the ICU Oxford textbook of critical care, 2nd edition. Antibiotic resistance in the ICU antibiotic resistance in the ICU. 2016;1-11.

35. Brusselaers $\mathrm{N}$, Vogelaers $\mathrm{D}, \mathrm{Blot} \mathrm{S}$. The rising problem of antimicrobial resistance in the intensive care unit. Ann Intensive Care. 2011;1 (1):47. http://www.annalsofintensivecare.com/content/1/1/47.

36. Zhanel GG, Decorby M, Nichol KA, Wierzbowski A, Baudry PJ, Karlowsky JA, et al. Antimicrobial susceptibility of 3931 organisms isolated from intensive care units in Canada: Canadian National Intensive Care Unit Study, 2005/2006. Diagn Microbiol Infect Dis. 2008;62:67-80.

\section{Publisher's Note}

Springer Nature remains neutral with regard to jurisdictional claims in published maps and institutional affiliations. 